\title{
Nitric oxide synthase 2A (NOS2A) polymorphisms are not associated with invasive pneumococcal disease Antony Payton ${ }^{1}$, Debbie Payne ${ }^{1}$, Limangeni A Mankhambo ${ }^{2}$, Daniel L Banda ${ }^{2}$, C Anthony Hart ${ }^{\dagger 3}$, William ER Ollier ${ }^{1}$ and Enitan D Carrol*2,3,4
}

Address: ${ }^{1}$ Centre for Integrated Genomic Medical Research, Stopford building, The University of Manchester, Oxford Road, Manchester, M13 9PT, UK, ${ }^{2}$ Malawi-Liverpool-Wellcome Trust Clinical Research Programme, PO Box 30096, Blantyre, Malawi, ${ }^{3}$ Division of Medical Microbiology, University of Liverpool, Daulby Street, Liverpool, L69 3GA, UK and ${ }^{4}$ Division of Child Health, University of Liverpool, Alder Hey Children's NHS Foundation Trust,, Eaton Road, Liverpool, L12 2AP, UK

Email: Antony Payton - Tony.Payton@man.ac.uk; Debbie Payne - Debbie.Payne@man.ac.uk; Limangeni A Mankhambo - lmankhambo@gmail.com; Daniel L Banda - dlbanda@mlw.medcol.mw; C Anthony Hart - h.c.kelly@liv.ac.uk; William ER Ollier - Bill.Ollier@man.ac.uk; Enitan D Carrol* - edcarrol@liv.ac.uk

* Corresponding author †Equal contributors

Published: 23 March 2009

BMC Medical Genetics 2009, 10:28 doi:10.1 186/147/-2350-10-28
Received: 5 February 2009

Accepted: 23 March 2009

This article is available from: http://www.biomedcentral.com/147I-2350/I0/28

(C) 2009 Payton et al; licensee BioMed Central Ltd.

This is an Open Access article distributed under the terms of the Creative Commons Attribution License (http://creativecommons.org/licenses/by/2.0), which permits unrestricted use, distribution, and reproduction in any medium, provided the original work is properly cited.

\begin{abstract}
Background: Streptococcus pneumoniae (pneumococcus) is responsible for over one million deaths per year, with young children, the elderly and immunocompromised individuals being most at risk. Approximately half of East African children have been reported to be asymptomatic carriers of pneumococcus with invasive infection occurring after the disruption of the respiratory membrane which is believed to be caused by the host immune response. Racial incidence of invasive pneumococcal disease (IPD) is higher in certain populations even after adjusting for environmental factors suggesting a genetic component to disease susceptibility. The nitric oxide synthase $2 \mathrm{~A}$ (NOS2A) gene is responsible for the production of nitric oxide under pathological conditions including host defence against bacterial infection. Nitric oxide is a modulator of apoptotic and inflammatory cascades and endothelial permeability. We hypothesised that genetic variants within this gene may predispose to disease risk and survival.
\end{abstract}

Methods: A cohort of 299 children with IPD (22I meningitis, 4I pneumonia and 37 with bacteraemia) and $93 \mathrm{I}$ age matched controls from Malawi were used in this study. We investigated nine haplotype tagging single nucleotide polymorphisms within the NOS2A gene and compared the presence or absence of the minor alleles in cases and controls and survivors and non-survivors within the cases.

Results: We observed no significant associations between cases and controls or with survival in either all IPD cases or in the separate analysis of meningitis cases. A near significant association was obtained for the comparison of rs8078340 in cases and controls ( $p$-value, 0.078 ). However, results were unadjusted for multiple testing.

Conclusion: Our results suggest that polymorphic variation within the NOS2A gene does not influence invasive pneumococcal disease susceptibility or survival. 


\section{Background}

The pneumococcus is a principal contributor towards serious illness particularly in young children from developing countries. It colonises the mucosal surface of the upper respiratory tract and has been reported to have a nasopharyngeal carriage of $57 \%, 41 \%$ and $6 \%$ in East African individuals aged $0-4,5-9$ and $10-85$ years, respectively [1]. Invasive infection is achieved by the disruption of the respiratory epithelial membrane which is believed to be initiated by the host's immune response in a Toll-like receptor 2 dependent manner $[2,3]$. This results in invasive pneumococcal disease (IPD) which includes pneumonia, meningitis and bacteraemia. Meningitis has the highest mortality rate (approximately 30\%) with 21\% of meningitis survivors suffering neurological deficits which include seizures, hearing loss and intellectual impairment [4]. HIV positive individuals have a higher incidence of disease with a reported 8.2 and 36.9-fold increase in adults and children, respectively [5]. Other factors such as overcrowding and exposure to smoke have also been associated with increased prevalence of IPD [6]. Disease severity is dependent upon a number of factors including age, co-morbid disease, pneumococcus strain, bacterial load and pneumolysin allelic variation [7]. Our group have shown that high blood and cerebral spinal fluid pneumococcal DNA loads are associated with a fatal outcome in Malawian children with IPD [8].

Certain racial groups including native American and Australian populations and African Americans have a higher incidence of IPD even after socio-economic factors have been adjusted for suggesting that genetic variation may predispose to disease development [9]. Current knowledge of genetic variation and immune response to IPD is limited although associations have been reported between polymorphisms within six genes of members of the family of inhibitors of nuclear factor (NF)-kappaB, NFKBIA and NFKBIE [10], the adaptor protein Mal [3], the Fc fragment of IgG, low affinity IIa, receptor (CD32) [11], interleukin-10 [12], C-reactive protein [13] and mannose-binding lectin (MBL) [14]. The only attempted replication of these findings has been with CD32 and MBL where subsequent investigations failed to find an association $[15,16]$.

Nitric oxide (NO) is a pleiotropic substance that has been shown to regulate vascular permeability, motor control and host defence against bacterial and parasitic infections [17-19]. Under non-pathological conditions neuronal and endothelial nitric oxide synthase (NOS1 and NOS3, respectively) are responsible for NO production by catalysing the breakdown of L-arginine into $\mathrm{NO}$ and L-citrulline. Whilst, NOS1 and NOS3 are involved in the immune response, another isoform of NOS called inducible NOS (NOS2) is responsible for a much greater expression of
NO in response to injury or infection [20]. NO is produced by the majority of immune response cells including alveolar macrophages which are the first cells involved in phagocytosis and early proinflammatory cytokine release during respiratory infection [21]. Successful phagocytosis of pneumococcus by macrophages has been shown to increase NOS2 and NO production [22]. This increase results in down-regulation of anti-apoptotic proteins, upregulation of pro-apoptotic proteins, mitochondrial membrane permeabilisation and ultimately apoptosis of the macrophage. In the same study NOS2 inhibitors reduced bacterial killing and shifted macrophage death from apoptotic to necrotic. Apoptosis has been shown to play an important role in neuronal cell death caused by IPD and this process is believed to be responsible for the high mortality in meningitis [23]. NOS2 has also been shown to influence the inflammatory response to bacterial lipopolysaccharide through the regulation of the cytokine response [24]. Brain protein levels of IL-1 $\beta$, IL-6, TNF- $\alpha$, MIP- $1 \alpha$, MIP- 2 are reduced in inducible NOS (iNOS) deficient, pneumococcal meningitis induced mice suggesting that iNOS derived NO plays a role in cytokine and chemokine upregulation [25]. This study also reported that iNOS-derived NO plays a role in peroxynitrite formation which disrupts the blood brain barrier. Finally, pneumolysin, a pore-forming hemolysin, and an important pneumococcal virulence factor has been shown to induce iNOS, and NO production in macrophages [26].

Here we investigate the influence of haplotype tagging SNPs (htSNPs) within the NOS2A gene (43.8 kb gene that codes for NOS2; chromosome position 17q11.2), on both disease susceptibility and survival in a cohort of children with IPD and age matched controls from Malawi.

\section{Methods \\ Study population}

The 299 children with IPD (aged 2 months to 16 years) recruited into this study were admitted from the Queen Elizabeth Central Hospital, Blantyre, Southern Malawi. HIV prevalence of paediatric inpatients in this area is $19 \%$ with $34 \%$ prevalence reported in children with bacterial meningitis $[27,28]$. Pneumococcal vaccine was not available and at time of admission only 2 participants were receiving antiretroviral therapy and 3 were on co-trimoxazole prophylaxis. Only children with confirmed IPD (by culture, PCR, microscopy or latex antigen tests) were included in the study. Pneumococcal pneumonia was confirmed by radiology and positive blood or lung aspirate by culture or PCR. Pneumococcal meningitis was confirmed by CSF cell count $\left(>10 \mu \mathrm{l}^{-1}\right)$ and one of the following tests: CSF culture, gram stain, polysaccharide antigen and/or pneumococcal PCR positive. Of the 299 cases, 221 were diagnosed with meningitis, 41 with pneu- 
monia and 37 with bacteraemia alone. Of the 41 cases with pneumococcal pneumonia, 13 (32\%) were bacteraemic by blood culture or PCR and 31 (78\%) were positive by PCR of lung aspirate. As the majority of patients with pneumococcal pneumonia do not have bacteraemia, we did not make this a requirement to fulfil the criteria of invasive pneumococcal disease. The number of cases who survived was 234 and the number who died was 65 . The 931 controls consisted of age matched, afebrile and aparasitemic children from the same villages as the cases. HIV status was determined by either Unigold (Trinity Biotech, Wicklow, Ireland), Serocard (Trinity Biotech, Wicklow, Ireland) or Determine-HIV (Abbott Diagnostics Ltd, Maidenhead, U.K.) in children over 18 months and Amplicor HIV-1 Test version 1.5 (Roche Diagnostics, Indianapolis, U.S.A.) in those under 18 months. Further details on laboratory methods and management protocols can be found elsewhere [8]. Ethical approval was obtained from both The College of Medicine Research and Ethics Committee and the Liverpool School of Tropical Medicine Research and Ethics Committee.

\section{Genotyping}

NOS2A polymorphism information was obtained from the HapMap http://www.hapmap.org Yoruba population data. Haploview Version 4.1 was used to select htSNPs, with an $\mathrm{r}^{2}$ threshold of 0.8 [29]. The htSNPs comprised: rs8078340, rs2779248, rs16966563, rs3794763, rs1137933, rs17718148, rs4796052, rs2297518, rs2314809, rs2297512. PCR reactions were carried out on PTC-225 Peltier Thermal Cyclers (MJ Research, Waltham, USA) in 384 well microtitre plates using $10 \mathrm{ng}$ of genomic DNA with a final reaction volume of $10 \mu \mathrm{l}$. Primer details and PCR conditions can be obtained from the corresponding author. Five replication samples and two blank controls were used as quality controls for each plate. Genotyping was performed using Sequenom ${ }^{\mathrm{TM}}$ technology (San Diego, USA). All laboratory work was performed under the ISO 9001:2000 quality management requirements.

\section{Analysis}

Hardy-Weinberg equilibrium was calculated using Golden Helixtree Genetics Analysis software version 5.0 (Golden Helix, Inc. MT, USA). The influence of genotype on cases and controls and survival in cases was performed in Stata v.8.2 (StataCorp, Texas, USA) using logistic regression analysis. The number of homozygous individuals for the minor allele was small $(<50)$ for the majority of genotypes and they were pooled with heterozygous individuals. Analysis was therefore performed for the presence or absence of the minor allele. Data were adjusted for bacterial load, HIV status, disease type (pneumonia, meningitis or bacteraemia), age and gender for the analysis of genotype and survival. HIV status was not available for the controls and therefore case-control analysis was only adjusted for age and gender. Survival analysis was performed on all IPD cases and meningitis cases separately. Survival in pneumonia and bacteraemia cases was not performed due to the low number of deaths in each group ( 6 and 7 , respectively).

\section{Results}

Minor allele frequencies (MAF), Hardy-Weinberg equilibrium (HWE) p-values and successful genotype call rates are given in Table 1. SNP rs2297518 had a low call rate success (33\%) and was excluded from analysis. MAF was compared against that given on HapMap for the Nigerian Yoruba in Ibadan (YRI) population. Five SNPs (rs2779248, rs16966563, rs1137933, rs4796052 and rs2297512) had similar frequencies ( $<3 \%$ difference). SNPs rs8078340, rs3794763, rs17718148, and rs2314809 had frequencies of $0.24,0.27,0.16$, and 0.38 in the Malawi controls and $0.13,0.11,0.01$, and 0.33 in the YRI population, respectively. MAF of our cases and controls were similar with the largest difference being $4 \%$ (rs8068149).

Association analysis results are given in Table 2. We observed no significant associations between cases and controls or with survival in either all IPD cases or in the

Table I: NOS2A htSNP gene position, minor allele frequencies (MAF), successful genotype call rates and Hardy-Weinberg equilibrium p-values (HWE P) in Malawi IPD cases and controls

\begin{tabular}{|c|c|c|c|c|c|c|}
\hline Reference SNP & Position & Nucleotide substitution & MAF case & MAF control & Call rate & HWE P \\
\hline rs8078340 & 5' near gene & $G>A$ & 0.27 & 0.24 & 0.97 & 0.13 \\
\hline rs2779248 & 5 ' near gene & $\mathrm{T}>\mathrm{C}$ & 0.46 & 0.45 & 0.99 & 0.70 \\
\hline rs 16966563 & Exon 4 Pro68Pro & $\mathrm{T}>\mathrm{C}$ & 0.26 & 0.26 & 0.97 & 0.95 \\
\hline rs3794763 & Intron 5 & $G>A$ & 0.27 & 0.27 & 0.98 & 0.43 \\
\hline rs|l37933 & Exon 10 Asp385Asp & $\mathrm{C}>\mathrm{T}$ & 0.14 & 0.17 & 0.97 & 0.85 \\
\hline rs $177|8| 48$ & Intron II & $\mathrm{C}>\mathrm{T}$ & 0.13 & 0.16 & 0.98 & 0.45 \\
\hline rs4796052 & Intron II & $\mathrm{C}>\mathrm{T}$ & 0.20 & 0.21 & 0.98 & 0.83 \\
\hline rs2297518 & Exon 16 Leu608Ser & $G>A$ & 0.25 & 0.25 & 0.33 & 0.36 \\
\hline rs2314809 & Intron 17 & $\mathrm{~T}>\mathrm{C}$ & 0.39 & 0.38 & 0.97 & 0.61 \\
\hline rs22975I2 & Intron 20 & $A>G$ & 0.16 & 0.16 & 0.97 & 0.92 \\
\hline
\end{tabular}


Table 2: Comparison of NOS2A htSNP allele frequencies between cases and controls and survival in cases

\begin{tabular}{|c|c|c|c|c|c|c|}
\hline \multirow[t]{2}{*}{ Reference SNP } & \multicolumn{2}{|c|}{ Homozygou wild-type } & \multicolumn{2}{|c|}{ Presence of minor allele } & \multirow[t]{2}{*}{ p-value } & \multirow[t]{2}{*}{$95 \%$ confidence interval for coefficient } \\
\hline & n (\%) & n (\%) & n (\%) & n (\%) & & \\
\hline & \multicolumn{6}{|l|}{ Case-control } \\
\hline & Cases & Controls & Cases & Controls & & \\
\hline rs8078340 & $172(59)$ & $485(54)$ & $122(4 \mid)$ & $412(46)$ & 0.078 & $-0.59,0.03$ \\
\hline rs2779248 & $260(88)$ & $797(87)$ & $37(12)$ & $121(13)$ & 0.431 & $-0.65,0.28$ \\
\hline rs 16966563 & $203(69)$ & $634(70)$ & $90(31)$ & $270(30)$ & $0.7 \mid 4$ & $-0.27,0.39$ \\
\hline rs3794763 & $193(65)$ & $575(63)$ & $102(35)$ & $337(37)$ & 0.331 & $-0.16,0.48$ \\
\hline rs II37933 & $183(63)$ & $580(64)$ & $109(37)$ & $326(36)$ & 0.908 & $-0.30,0.34$ \\
\hline rs 17718148 & $212(72)$ & $677(75)$ & $81(28)$ & $229(25)$ & 0.718 & $-0.28,0.40$ \\
\hline rs4796052 & $201(67)$ & $673(73)$ & $97(33)$ & $240(27)$ & 0.106 & $-0.06,0.59$ \\
\hline rs2314809 & $158(55)$ & $485(54)$ & $131(45)$ & $415(46)$ & 0.956 & $-0.32,0.30$ \\
\hline \multirow[t]{3}{*}{ rs22975I 2} & $157(53)$ & $496(55)$ & $138(47)$ & $407(45)$ & 0.913 & $-0.29,0.32$ \\
\hline & \multicolumn{6}{|c|}{ Survival (all IPD cases) } \\
\hline & Non-survivors & Survivors & Non-survivors & Survivors & & \\
\hline rs8078340 & $33(5 \mathrm{I})$ & $139(6 \mid)$ & $32(49)$ & $90(39)$ & 0.675 & $-1.09,0.70$ \\
\hline rs2779248 & $57(88)$ & $203(88)$ & $8(12)$ & $29(12)$ & 0.936 & $-1.14,1.24$ \\
\hline rs 16966563 & $41(63)$ & $162(7 \mid)$ & $24(37)$ & $66(29)$ & 0.935 & $-0.90,0.98$ \\
\hline rs3794763 & $39(60)$ & $154(67)$ & $26(40)$ & $76(33)$ & 0.101 & $-0.16,1.75$ \\
\hline rsII37933 & $36(56)$ & 147 (64) & $28(44)$ & $81(36)$ & 0.592 & $-0.68,1.19$ \\
\hline rs $177|8| 48$ & $40(62)$ & $172(74)$ & $25(38)$ & $59(26)$ & 0.811 & $-1.11,0.86$ \\
\hline rs4796052 & $40(62)$ & 161 (69) & $25(38)$ & $72(31)$ & 0.194 & $-1.54,0.31$ \\
\hline rs2314809 & $37(58)$ & $121(54)$ & $27(42)$ & $104(46)$ & 0.684 & $-0.72,1.10$ \\
\hline \multirow[t]{3}{*}{ rs22975I 2} & $37(57)$ & $12 \mid(52)$ & $28(43)$ & $110(48)$ & 0.558 & $-0.64,1.19$ \\
\hline & \multicolumn{6}{|c|}{ Survival (meningitis cases only) } \\
\hline & Non-survivors & Survivors & Non-survivors & Survivors & & \\
\hline rs8078340 & $27(47)$ & $100(62)$ & $30(53)$ & $61(38)$ & 0.567 & $-1.20,0.66$ \\
\hline rs2779248 & $49(86)$ & $138(85)$ & $8(14)$ & $24(15)$ & 0.783 & $-1.37,1.03$ \\
\hline rs16966563 & $35(61)$ & $112(70)$ & $22(39)$ & $47(30)$ & 0.608 & $-0.93,0.55$ \\
\hline rs3794763 & $35(61)$ & $105(65)$ & $22(39)$ & $56(35)$ & 0.117 & $-0.20,1.77$ \\
\hline rsII37933 & $35(63)$ & $99(62)$ & $21(37)$ & $60(38)$ & 0.623 & $-0.72,1.21$ \\
\hline rs 17718148 & $38(67)$ & $118(73)$ & $19(33)$ & $44(27)$ & 0.634 & $-1.25,0.76$ \\
\hline rs4796052 & $37(65)$ & $114(70)$ & $20(35)$ & $49(30)$ & 0.153 & $-1.66,0.26$ \\
\hline rs2314809 & $31(55)$ & $86(54)$ & $25(45)$ & $73(46)$ & 0.666 & $-0.75,1.17$ \\
\hline rs22975I2 & $32(56)$ & $89(55)$ & $25(44)$ & $73(45)$ & 0.521 & $-0.64,1.26$ \\
\hline
\end{tabular}

Data adjusted for age and sex

separate analysis of meningitis cases. A near significant association was obtained for the comparison of rs8078340 in cases and controls ( $p$-value, 0.078). However, results were unadjusted for multiple testing and the near significant association likely occurred by chance given we performed 27 comparisons.

\section{Discussion}

We have investigated nine htSNPs that span the NOS2A gene and found that they do not influence disease suscep- tibility or survival in a Malawi IPD cohort. These results suggest either NOS2A polymorphisms are not associated with the disease or that the genetic effect size was too small for our cohort of 299 cases and 931 controls to detect. This sample size gives us $85 \%$ power to detect an odds ratio of 1.5 for our cases and controls assuming a minor allele frequency of 0.25 (average of our htSNPs) and a significance level of 0.05 . Subdividing our cases by survival reduces power to $82 \%$ for detecting an odds ratio of 2.4 using the same parameters. Given the high levels of 
NO that are produced in response to pneumococcal infection it may be reasonable to assume that a genetic effect would have to be large to impact on disease conversion or severity. However, sample size is a limiting factor for this study especially for the analysis of survival where we are comparing 65 non-survivors against 234 survivors.

Associations between NOS2A polymorphisms and other diseases have previously been reported. The exon 10 SNP rs1137933 has been associated with Crohns disease and the promoter SNP rs2779248 has been associated with ulcerative colitis [30]. In addition, an exon 16 SNP rs2297518 has been implicated in type-1 diabetes susceptibility, risk of non-Hodgkin lymphoma and atrophic gastritis [31-33]. Unfortunately, rs2297518 was excluded from our analysis due to a low genotype success. This nonsynonymous SNP (Leu608Ser) cannot therefore be excluded from association with IPD. The largest study of NOS2A variation in multiple sclerosis demonstrated that common variation within NOS2A alone does not appear to significantly influence disease severity [34].

\section{Conclusion}

Whilst we cannot rule out that NOS2A influences disease susceptibility or severity to IPD, our results suggest the impact if any will be small. However, evidence from other studies suggest that the immune response is important both in the conversion of the asymptomatic carriage to causing invasive disease and in the severity of the disease. Other immune response genes should therefore be the focus of future IPD genetic association studies.

\section{Abbreviations}

NOS2A: nitric oxide synthase 2A; IPD: invasive pneumococcal disease; NO: Nitric oxide; iNOS: inducible nitric oxide synthase.

\section{Competing interests}

The authors declare that they have no competing interests.

\section{Authors' contributions}

$\mathrm{AP}$ and DP carried out the genotyping. AP performed the statistical analysis AP and EDC drafted the manuscript. EDC, LAM and DLB recruited the patients and controls. EDC, CAH and WERO participated in the design of the study. All authors read and approved the final manuscript.

\section{Acknowledgements}

The IPD (Invasive Pneumococcal Disease) Study Group (Nurses: C Antonio, M Chinamale, L Jere, D Mnapo, V Munthali, F Nyalo, J Simwinga, Clinical Officer: M Kaole, Field Workers: A Manyika, K Phiri). We thank the children included in this study, and their parents and guardians for giving consent for them to participate in the study. We also extend thanks to the nursing and medical staff, at the Malawi-Liverpool-Wellcome Trust Clinical Research Programme (MLW), Research Ward, for their contribution to this study. The former (Malcolm E Molyneux) and current (Robert S Hey- derman) directors of the MLW Clinical research Programme, and the Head of the Paediatric Department at the University of Malawi (Elizabeth M Molyneux) provided scientific and institutional support for the study. EDC was supported by a Wellcome Trust Career Development Grant (Grant No. 068026).

\section{References}

I. Abdullahi O, Nyiro J, Lewa P, Slack M, Scott JA: The descriptive epidemiology of Streptococcus pneumoniae and Haemophilus influenzae nasopharyngeal carriage in children and adults in Kilifi district, Kenya. Pediatr Infect Dis J 2008, 27(I):59-64.

2. Beisswenger C, Coyne CB, Shchepetov M, Weiser JN: Role of p38 MAP kinase and transforming growth factor-beta signaling in transepithelial migration of invasive bacterial pathogens. J Biol Chem 2007, 282(39):28700-28708.

3. Khor CC, Chapman SJ, Vannberg FO, Dunne A, Murphy C, Ling EY, Frodsham AJ, Walley AJ, Kyrieleis O, Khan A, et al.: A Mal functional variant is associated with protection against invasive pneumococcal disease, bacteremia, malaria and tuberculosis. Nat Genet 2007, 39(4):523-528.

4. Aronin SI, Peduzzi P, Quagliarello VJ: Community-acquired bacterial meningitis: risk stratification for adverse clinical outcome and effect of antibiotic timing. Ann Intern Med 1998, I 29( I I):862-869.

5. Jones N, Huebner R, Khoosal M, Crewe-Brown H, Klugman K: The impact of HIV on Streptococcus pneumoniae bacteraemia in a South African population. Aids 1998, I 2( I 6):2 I 77-2 184.

6. O'Dempsey TJ, McArdle TF, Morris J, Lloyd-Evans N, Baldeh I, Laurence BE, Secka O, Greenwood BM: A study of risk factors for pneumococcal disease among children in a rural area of west Africa. Int J Epidemiol 1996, 25(4):885-893.

7. Jefferies JM, Johnston CH, Kirkham LA, Cowan GJ, Ross KS, Smith A Clarke SC, Brueggemann AB, George RC, Pichon B, et al.: Presence of nonhemolytic pneumolysin in serotypes of Streptococcus pneumoniae associated with disease outbreaks. I Infect Dis 2007, I 96(6):936-944.

8. Carrol ED, Guiver M, Nkhoma S, Mankhambo LA, Marsh J, Balmer P, Banda DL, Jeffers G, White SA, Molyneux EM, et al.: High pneumococcal DNA loads are associated with mortality in Malawian children with invasive pneumococcal disease. Pediatr Infect Dis J 2007, 26(5):416-422.

9. Henneberger PK, Galaid EI, Marr JS: The descriptive epidemiology of pneumococcal meningitis in New York City. Am J Epidemiol 1983, I I 7(4):484-49I.

10. Chapman SJ, Khor CC, Vannberg FO, Frodsham A, Walley A, Maskell NA, Davies CW, Segal S, Moore CE, Gillespie SH, et al.: IkappaB genetic polymorphisms and invasive pneumococcal disease. Am J Respir Crit Care Med 2007, I 76(2): I81-I87.

II. Yuan FF, Wong M, Pererva N, Keating J, Davis AR, Bryant JA, Sullivan JS: FcgammaRIIA polymorphisms in Streptococcus pneumoniae infection. Immunol Cell Biol 2003, 81(3): I92-195.

12. Schaaf BM, Boehmke F, Esnaashari H, Seitzer U, Kothe H, Maass M, Zabel P, Dalhoff K: Pneumococcal septic shock is associated with the interleukin-10-1082 gene promoter polymorphism. Am J Respir Crit Care Med 2003, I 68(4):476-480.

13. Roy S, Hill AV, Knox K, Griffiths D, Crook D: Research pointers: Association of common genetic variant with susceptibility to invasive pneumococcal disease. Bmj 2002, 324(7350): 1369.

14. Roy S, Knox K, Segal S, Griffiths D, Moore CE, Welsh KI, Smarason A, Day NP, McPheat WL, Crook DW, et al:: MBL genotype and risk of invasive pneumococcal disease: a case-control study. Lancet 2002, 359(93 I 7): I 569-I573.

I5. Moens L, Van Hoeyveld E, Verhaegen J, De Boeck K, Peetermans WE, Bossuyt $X$ : Fcgamma-receptor IIA genotype and invasive pneumococcal infection. Clin Immunol 2006, I I 8(I):20-23.

16. Kronborg G, Weis N, Madsen HO, Pedersen SS, Wejse C, Nielsen H, Skinhoj P, Garred P: Variant mannose-binding lectin alleles are not associated with susceptibility to or outcome of invasive pneumococcal infection in randomly included patients. J Infect Dis 2002, I 85(10): I5 I7-1520.

17. Marriott HM, Hellewell PG, Whyte MK, Dockrell DH: Contrasting roles for reactive oxygen species and nitric oxide in the innate response to pulmonary infection with Streptococcus pneumoniae. Vaccine 2007, 25(I3):2485-2490. 
18. Del Bel EA, Guimaraes FS, Bermudez-Echeverry M, Gomes MZ, Schiaveto-de-souza A, Padovan-Neto FE, Tumas V, Barion-Cavalcanti AP, Lazzarini M, Nucci-da-Silva LP, et al.: Role of nitric oxide on motor behavior. Cell Mol Neurobiol 2005, 25(2):37I-392.

19. Gentiloni Silveri N, Mazzone M, Portale G, Carbone L: Nitric oxide. A general review about the different roles of this innocent radical. Minerva Med 200I, 92(3): I67-I7I.

20. Bogdan C: Nitric oxide and the immune response. Nat Immunol 200I, 2(I 0):907-9I6.

21. Gordon SB, Read RC: Macrophage defences against respiratory tract infections. Br Med Bull 2002, 6 I:45-6I.

22. Marriott HM, Ali F, Read RC, Mitchell T], Whyte MK, Dockrell DH: Nitric oxide levels regulate macrophage commitment to apoptosis or necrosis during pneumococcal infection. FASEB | 2004, I 8( I 0): I | 26- I I 28.

23. Tuomanen El: Molecular and cellular mechanisms of pneumococcal meningitis. Ann N Y Acad Sci 1996, 797:42-52.

24. Speyer CL, Neff TA, Warner RL, Guo RF, Sarma JV, Riedemann NC, Murphy ME, Murphy HS, Ward PA: Regulatory effects of iNOS on acute lung inflammatory responses in mice. Am J Pathol 2003 I 63(6):2319-2328.

25. Winkler F, Koedel U, Kastenbauer S, Pfister HW: Differential expression of nitric oxide synthases in bacterial meningitis: role of the inducible isoform for blood-brain barrier breakdown. J Infect Dis 200।, I 83( I 2): I749-I759.

26. Braun JS, Novak R, Gao G, Murray PJ, Shenep JL: Pneumolysin, a protein toxin of Streptococcus pneumoniae, induces nitric oxide production from macrophages. Infect Immun 1999 67(8):3750-3756.

27. Rogerson SR, Gladstone M, Callaghan M, Erhart L, Rogerson SJ, Borgstein $E$, Broadhead RL: HIV infection among paediatric inpatients in Blantyre, Malawi. Trans R Soc Trop Med Hyg 2004 98(9):544-552.

28. Molyneux EM, Tembo M, Kayira K, Bwanaisa L, Mweneychanya J Njobvu A, Forsyth H, Rogerson S, Walsh AL, Molyneux ME: The effect of HIV infection on paediatric bacterial meningitis in Blantyre, Malawi. Arch Dis Child 2003, 88( I 2): I I I 2- I I I8.

29. Barrett JC, Fry B, Maller J, Daly MJ: Haploview: analysis and visualization of LD and haplotype maps. Bioinformatics 2005 2 I(2):263-265.

30. Martin MC, Martinez A, Mendoza JL, Taxonera C, Diaz-Rubio M, Fernandez-Arquero M, de la Concha EG, Urcelay E: Influence of the inducible nitric oxide synthase gene (NOS2A) on inflammatory bowel disease susceptibility. Immunogenetics 2007 , 59(I I):833-837.

31. Johannesen J, Pie A, Pociot F, Kristiansen OP, Karlsen AE, Nerup J: Linkage of the human inducible nitric oxide synthase gene to type I diabetes. J Clin Endocrinol Metab 200I, 86(6):2792-2796.

32. Wang SS, Davis S, Cerhan JR, Hartge P, Severson RK, Cozen W, Lan $\mathrm{Q}$, Welch R, Chanock S], Rothman N: Polymorphisms in oxidative stress genes and risk for non-Hodgkin lymphoma. Carcinogenesis 2006, 27(9): 1828-1834.

33. Canzian F, Franceschi S, Plummer M, van Doorn LJ, Lu Y, Gioia-Patricola L, Vivas J, Lopez G, Severson RK, Schwartz AG, et al.: Genetic polymorphisms in mediators of inflammation and gastric precancerous lesions. Eur J Cancer Prev 2008, I 7(2): I 78- I83.

34. Barcellos LF, Ramsay PP, Caillier SJ, Sawcer S, Haines J, Schmidt S, Pericak-Vance M, Compston DA, Gabatto P, Hauser SL, et al.: Genetic variation in nitric oxide synthase 2A (NOS2A) and risk for multiple sclerosis. Genes Immun 2008, 9(6):493-500.

\section{Pre-publication history}

The pre-publication history for this paper can be accessed here:

http://www.biomedcentral.com/1471-2350/10/28/pre pub
Publish with Biomed Central and every scientist can read your work free of charge

"BioMed Central will be the most significant development for disseminating the results of biomedical research in our lifetime. "

Sir Paul Nurse, Cancer Research UK

Your research papers will be:

- available free of charge to the entire biomedical community

- peer reviewed and published immediately upon acceptance

- cited in PubMed and archived on PubMed Central

- yours - you keep the copyright
BioMedcentral 